Full-length article

\title{
Scutellarein inhibits hypoxia- and moderately-high glucose-induced pro- liferation and VEGF expression in human retinal endothelial cells ${ }^{1}$
}

\author{
Rong $\mathrm{GAO}^{2}$, Bang-hao $\mathrm{ZHU}^{2,5}$, Shi-bo TANG ${ }^{3}$, Jiang-feng $\mathrm{WANG}^{2}$, Jun $\mathrm{REN}^{4}$ \\ ${ }^{2}$ Department of Pharmacology and ${ }^{3}$ Zhongshan Ophthalmic Center, Sun Yat-sen University, Guangzhou 510080, China; ${ }^{4}$ Center for Cardio- \\ vascular Research and Alternative Medicine, University of Wyoming, Laramie, WY 82071, USA
}

\author{
Key words \\ scutellarein; human retinal endothelial cells; \\ vascular endothelial growth factor; hypoxia; \\ high glucose; diabetic retinopathy \\ ${ }^{1}$ This work was supported by a joint project \\ of the National Education Ministry and \\ Guangdong Province (No 2007B090400089). \\ ${ }^{5}$ Correspondence to Dr Bang-hao ZHU \\ Phn 86-20-8733-4786. \\ Fax 86-20-8733-1155. \\ E-mailzhubh@mail.sysu.edu.cn
}

Received 2007-12-03

Accepted 2008-03-10

doi: $10.1111 /$ j.1745-7254.2008.00797.x

\begin{abstract}
Aim: This study was designed to examine the effect of scutellarein on high glucose- and hypoxia-stimulated proliferation of human retinal endothelial cells (HREC). Methods: HREC were cultured under normal glucose (NG), moderate, and high glucose (NG supplemented with 10 or $25 \mathrm{mmol} / \mathrm{L} D$-glucose) and/or hypoxic (cobalt chloride treated) conditions. Cell proliferation was evaluated by a cell counting kit. The expression of vascular endothelial growth factor (VEGF) was assessed by Western blot analysis. Results: The proliferation of HREC was significantly elevated in response to moderately-high glucose and hypoxic conditions. The combination of high glucose and hypoxia did not have any additive effects on cell proliferation. Consistent with the proliferation data, the expression of VEGF was also upregulated under both moderately-high glucose and hypoxic conditions. The treatment with scutellarein $\left(1 \times 10^{-11}-1 \times 10^{-5} \mathrm{~mol} / \mathrm{L}\right)$ significantly inhibited high glucose- or hypoxia-induced cell proliferation and VEGF expression. Conclusion: Both hypoxia and moderately-high glucose were potent stimuli for cell proliferation and VEGF expression in HREC without any significant additive effects. Scutellarein is capable of inhibiting the proliferation of HREC, which is possibly related to its ability to suppress the VEGF expression.
\end{abstract}

\section{Introduction}

Diabetic retinopathy is one of the most commonly seen ocular complications of diabetes, affecting approximately three-fourths of the diabetic population within 15 years of disease onset. Early clinical signs of diabetic retinopathy include micro aneurysms and hemorrhages, whereas the later signs encompass dilated, tortuous irregular veins and retinal non-profusion, leading to retinal ischemia that ultimately results in neovascularization, a stage often referred to as proliferative retinopathy, which is characterized by the growth of new blood vessels on the surface of the retina. As a primary pathogenic factor in the development of diabetic complication ${ }^{[1,2]}$ hyperglycemia contributes to retinal capillary damage, including pericyte $\operatorname{loss}^{[3,4]}$ and alterations in retinal hemodynamics ${ }^{[5-8]}$, which results in a hypoxic state and increased tissue production of angiogenic factors in both early and late stages of diabetic retinopathy. While a number of growth factors and cytokines have been implicated to play a role in the pathogenesis of retinal neovascular diseases, vascular endothelial growth factor (VEGF) may serve as a primary mediator of the vascular pathology of diabetic retinopathy ${ }^{[6,7]}$. The expression of VEGF is known to be upregulated by hypoxia, oxidative stress, high glucose, and inflammatory reactions. In addition, VEGF receptors with high affinity and high sensitivity are present in retinal endothelial cell membranes, the levels of which are believed to be upregulated by a number of cardiovascular morbidities, especially diabetes ${ }^{[8,9]}$.

Retinal endothelial cells, which form the inner vascular lining, are prone to injury triggered by oxygen stress and hyperglycemia. In retinal endothelial cells, elevated levels of extracellular glucose have been demonstrated to activate protein kinase $\mathrm{C}$ (PKC) and consequently upregulate the VEGF expression ${ }^{[10,11]}$. Similar to hyperglycemia, hypoxia is 
another potent stimulator of VEGF expression. Exposure to hypoxia and advanced glycation end products may impose an additive effect on the expression of VEGF in retinal endothelial cells ${ }^{[12]}$, indicating that hypoxia and hyperglycemia may regulate the VEGF expression through independent mechanisms. This notion has received support from the observation that hypoxia regulates the VEGF expression via the increased binding of the active form of hypoxia inducible factor (HIF)-1 $\alpha$ to the hypoxic response element of the VEGF promoter. In addition, the increased stability of VEGF mRNA through the mitogen-activated protein kinase and Akt pathways have been implicated in the hypoxia-induced elevation of VEGF expression ${ }^{[13]}$. Similarly, hyperglycemia may promote the VEGF expression en route to the proliferation of endothelial cells, extracellular matrix, and pathology of angiogenesis. It is thus reasonable to speculate that hyperglycemia and hypoxia may work in synergy in the progression of diabetic retinopathy.

Scutellarein $\left(M_{\mathrm{r}}=462.21\right)$, one of the flavonoids isolated from the Chinese herb Erigeron breviscapus, has been used clinically for a long time in the treatment of cardiovascular diseases, cerebral infarction, and stroke in China. However, the therapeutic mechanism behind the beneficial effect of scutellarein has not been clearly elucidated. Scutellarein was shown to improve cerebral blood flow, micro-circulation, inhibit PKC, and prevent ischemic cerebral cell apoptosis ${ }^{[14-15]}$. Our earlier study depicted that scutellarein is capable of preventing endothelial dysfunction in diabetic rats ${ }^{[16]}$, suggesting a potential role of scutellarein in the management of diabetic complications. PKC activation may upregulate the VEGF expression ${ }^{[17]}$, and vice versa. VEGF signaling may involve PKC activation, resulting in the stimulation of endothelial cell migration and proliferation, en route to angiogenesis $^{[18-24]}$. Therefore, this study was designed to evaluate the effect of scutellarein on the proliferation of human retinal endothelial cells (HREC) and VEGF expression under high glucose and/or hypoxic conditions.

\section{Materials and methods}

Reagents Fetal bovine serum (FBS) was purchased from MDgenics (St Louis, MO, USA). The human endothelial medium and penicillin-streptomycin were obtained from Gibco BRL (Burlington, Ontario, Canada). $\beta$-Endothelial cell growth factor ( $\beta$-ECGF), trypsinase, phenylmethylsulfonyl fluoride, cobalt chloride $\left(\mathrm{CoCl}_{2}\right), D$-glucose, and $D$-mannitol were purchased from Sigma (St Louis, MO, USA). A polyclonal antibody against VEGF was obtained from Santa Cruz Biotechnology (Santa Cruz, CA, USA). Cell counting kit-8 was purchased from Dojindo (Kumamoto, Japan). The human VEGF ELISA kit was purchased from Guangzhou Zhanchen Biotech (Guangdong, China). Scutellarein was obtained from Yunnan Plant Pharmaceutical Factory (purity> 98.5\%; Yunnan, China).

HREC culture HREC were isolated as previously described $^{[18]}$. The cells were grown in a human endothelial medium supplemented with 10\% FBS, $5 \mu \mathrm{g} / \mathrm{L} \beta$-ECGF, and $1 \%(v / v)$ penicillin-streptomycin at $37^{\circ} \mathrm{C}$ in $5 \% \mathrm{CO}_{2}$ and $95 \%$ air atmosphere. The cells were trypsinized and subcultured in $25-\mathrm{cm}^{2}$ culture flasks or a 96 -well plate according to the appropriate assay conditions. The number of live cells was counted using a blood counting instrument after $0.4 \%$ trypan blue staining. Cells at passages 3 to 6 were used in all experiments.

HREC proliferation assay HREC were trypsinized (trypsinase-EDTA) and seeded in 96-well plates (approxi-mately 5000 cells/well). Following overnight incubation, the cells were transferred to a serum-free medium (without $\beta$-ECGF) and were further incubated for $24 \mathrm{~h}$. Then they were treated with different concentrations of scutellarein in growth medium with or without $150 \mu \mathrm{mol} / \mathrm{L} \mathrm{CoCl}_{2}$ for 48 or $72 \mathrm{~h}$ (which triggers cellular chemical hypoxia). A separate cohort of HREC was exposed to normal glucose (NG; $5 \mathrm{mmol} / \mathrm{L} D$-glucose), $15 \mathrm{mmol} / \mathrm{L} D$-glucose (NG supplemented with $10 \mathrm{mmol} / \mathrm{L} D$-glucose) and 30 $\mathrm{mmol} / \mathrm{L} D$-glucose (NG supplemented with $25 \mathrm{mmol} / \mathrm{L} D$ glucose) in the presence or absence of $\mathrm{CoCl}_{2}$ medium and treated with $1 \times 10^{-8} \mathrm{~mol} / \mathrm{L}$ scutellarein for $48 \mathrm{~h}$. $D$-Mannitol was used as an osmotic control. For the quantitative analysis of cell viability, $10 \mu \mathrm{L}$ of a cell counting kit-8 solution was added to each vial followed by a 1 -h incubation at $37^{\circ} \mathrm{C}$ in a humidified $\mathrm{CO}_{2}$ incubator. Absorbance at $450 \mathrm{~nm}$ was monitored with a microplate reader (Bio-TEK, Winooski, VT, USA).

Western blot analysis Twenty-five micrograms of total cellular proteins were separated by electrophoresis using $8 \%$ SDS-PAGE and transferred to a polyvinylidene fluoride membrane using a trans-blot cell system (Bio-Rad, Hercules, CA, USA). The membrane was blocked for $1 \mathrm{~h}$ at room temperature with phosphate-buffered saline (PBS)/Tween-20 (0.1\%) containing 5\% fat-free milk. After 3 washes with PBS/Tween20 , the membrane was incubated overnight at $4{ }^{\circ} \mathrm{C}$ with appropriate antibodies (1:300) in PBS/Tween-20. The membrane was then washed with PBS/Tween-20 and incubated for $2 \mathrm{~h}$ at room temperature with a horseradish peroxidase-conjugated goat antirabbit immunoglobulin G (1:2000). Antigen detection was performed with an enhanced chemiluminescence detection system (Cell Signaling Technology, Danvers, MA, USA).

ELISA The conditioned media from HREC treated with 
or without scutellarein $\left(1 \times 10^{-8} \mathrm{~mol} / \mathrm{L}\right)$ was subjected to human VEGF ELISA. Absorbance at $490 \mathrm{~nm}$ was measured in a microplate reader. The standard graph was drawn.

Statistical analysis All experiments were performed at least in triplicate. Results are expressed as mean $\pm \mathrm{SD}$ values. Student's $t$-test was used to determine statistical significance in the proliferation studies and normalized Western blot data. A $P$-value $<0.05$ was considered statistically significant.

\section{Results}

Effect of scutellarein on the proliferation of HREC under normal conditions Under normal conditions, scutellarein at the concentration of $1 \times 10^{-5}-1 \times 10^{-11} \mathrm{~mol} / \mathrm{L}$ displayed little effect on the proliferation of HREC. However, a higher concentration $\left(1 \times 10^{-4} \mathrm{~mol} / \mathrm{L}\right)$ of scutellarein significantly inhibited the proliferation of HREC $(P<0.05)$ following the 48 or $72 \mathrm{~h}$ treatment (Figure 1).

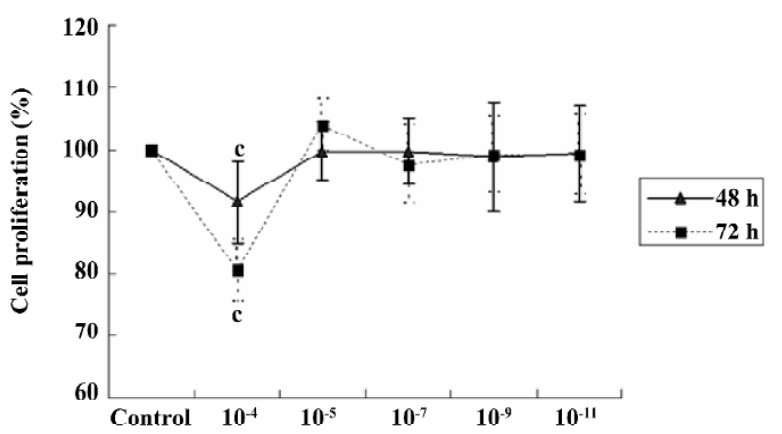

Figure 1. Effect of scutellarein on the proliferation of HREC under normal conditions following either 48 or $72 \mathrm{~h}$ of incubation. $n=6$. Mean \pm SD. ${ }^{\mathrm{c}} P<0.01$ vs control.

Effect of high glucose on the proliferation of HREC Compared with the NG control, the proliferation of HREC was significantly increased (up to $120.08 \% \pm 3.95 \%, P<0.05$ ) when HREC were cultured in $15 \mathrm{mmol} / \mathrm{L} D$-glucose for $48 \mathrm{~h}$. However, no significant effect was seen when HREC were cultured with $30 \mathrm{mmol} / \mathrm{L} D$-glucose for $48 \mathrm{~h}$. The osmotic control $(D$ mannitol) exhibited little effect on cell proliferation in HREC (Figure 2).

Effect of scutellarein on the hypoxia-induced proliferation of HREC Following the $48 \mathrm{~h}$ treatment of $\mathrm{CoCl}_{2}$ in growth medium, the proliferation of HREC was significantly enhanced (up to $133.80 \% \pm 8.96 \%, P<0.05$ compared with the control). The co-incubation of various concentrations of scutellarein $\left(1 \times 10^{-11}-1 \times 10^{-5} \mathrm{~mol} / \mathrm{L}\right)$ significantly antagonized the $\mathrm{CoCl}_{2}-$ induced effect on cell proliferation (Figure 3).

Effect of scutellarein on the hypoxia and/or high glucose-induced proliferation of HREC Given that the prolif-

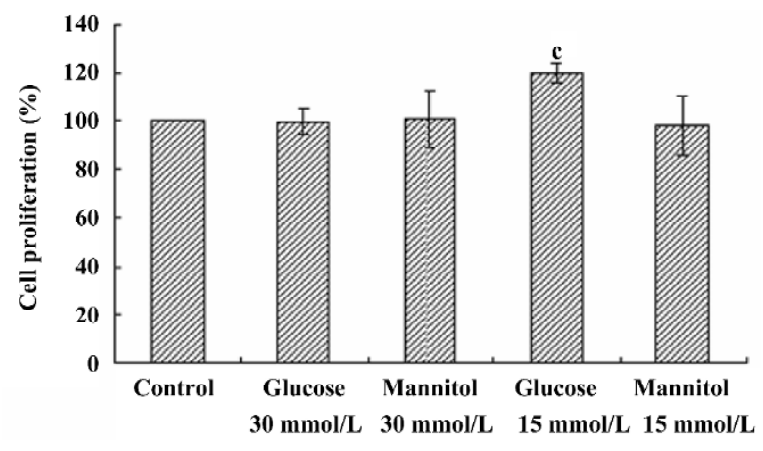

Figure 2. Effect of moderately-high $(15 \mathrm{mmol} / \mathrm{L})$ and high $(30$ $\mathrm{mmol} / \mathrm{L})$ glucose on the proliferation of HREC. $n=6$. Mean $\pm \mathrm{SD}$. ${ }^{\mathrm{c}} P<0.01$ vs control.

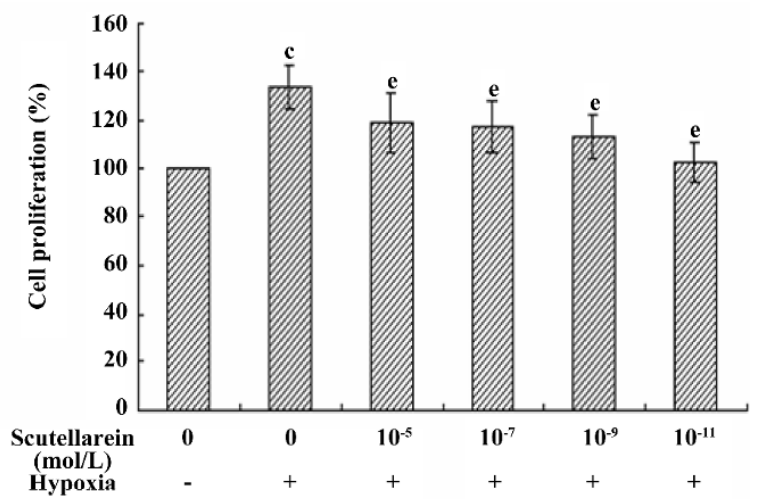

Figure 3. Effect of scutellarein $\left(1 \times 10^{-5}-1 \times 10^{-11} \mathrm{~mol} / \mathrm{L}\right)$ on the hypoxia-induced proliferation of HREC. $n=6$. Mean \pm SD. ${ }^{\mathrm{c}} P<0.01$ vs control. ${ }^{\mathrm{e}} P<0.05$ vs the hypoxia group.

eration of HREC was significantly enhanced when they were cultured with either $15 \mathrm{mmol} / \mathrm{L} D$-glucose or $\mathrm{CoCl}_{2}$, the possible synergy between high glucose and $\mathrm{CoCl}_{2}$ on the proliferation of HREC was examined. Our results showed that the concurrent treatment of high glucose and $\mathrm{CoCl}_{2}$ failed to elicit any additional effects in the proliferation of HREC compared with either condition alone. Nonetheless, the treatment with scutellarein $\left(1 \times 10^{-8} \mathrm{~mol} / \mathrm{L}\right)$ significantly inhibited the concurrent effect on proliferation of HREC from high glucose and $\mathrm{CoCl}_{2}$ (Figure 4).

VEGF protein expression in different treated conditions Consistent with our data from the proliferations of HREC, the VEGF protein expression was significantly upregulated in response to moderately-high glucose and hypoxic conditions, the effect of which was ablated by the treatment with scutellarein $\left(1 \times 10^{-8} \mathrm{~mol} / \mathrm{L}\right.$; Figure $\left.5 \mathrm{~A}, 5 \mathrm{~B}\right)$.

VEGF concentrations in the supernatants of different treated groups The VEGF concentration in the supernatant of the hypoxic-treated group was increased significantly compared with that of the control group. The treatment with 


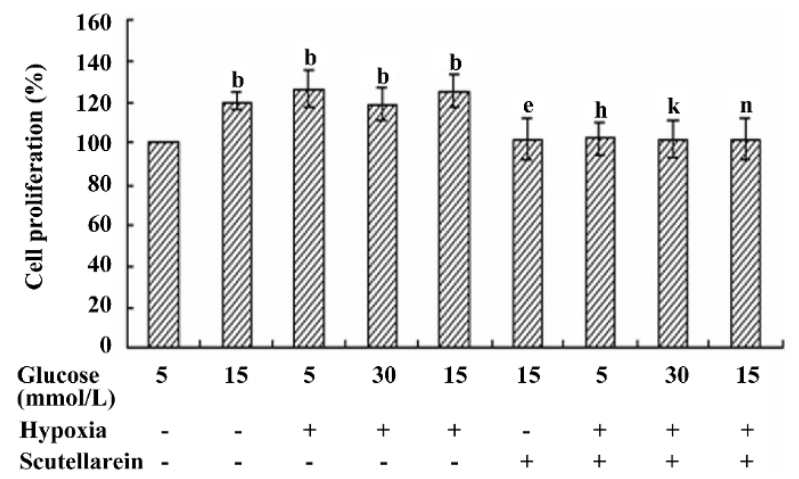

Figure 4. Effect of scutellarein $\left(1 \times 10^{-8} \mathrm{~mol} / \mathrm{L}\right)$ on hypoxia, moderately-high $(15 \mathrm{mmol} / \mathrm{L})$, and high $(30 \mathrm{mmol} / \mathrm{L})$ glucose-induced proliferation of HREC. Level of $5 \mathrm{mmol} / \mathrm{L}$ was deemed as a normal glucose level. $n=6$. Mean $\pm \mathrm{SD}$. ${ }^{\mathrm{b}} P<0.05$ vs control; ${ }^{\mathrm{e}} P<0.05$ vs moderately-high glucose group; ${ }^{\mathrm{h}} P<0.05 \mathrm{vs}$ the hypoxia group; ${ }^{\mathrm{k}} \mathrm{P}<$ 0.05 vs high glucose+hypoxia group; ${ }^{\mathrm{n}} P<0.05$ vs moderately-high glucose+hypoxia group.
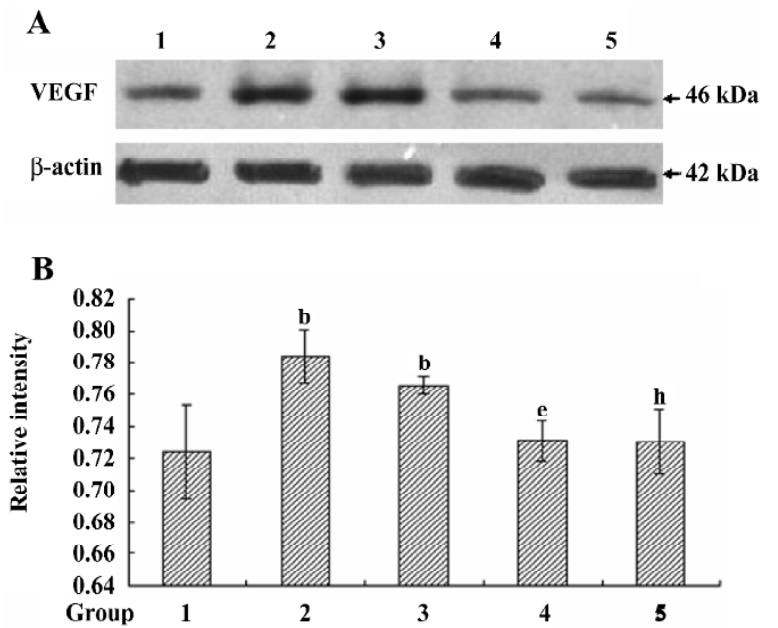

Figure 5. VEGF protein expression in HREC under different conditions. (A) representative gel blots depicting VEGF and loading control $\beta$-actin using specific antibodies; (B) arbitrary optical density of the VEGF protein expression (normalized to that of $\beta$ actin). $n=6$. Mean \pm SD. ${ }^{\mathrm{b}} P<0.05$ vs control; ${ }^{\mathrm{e}} P<0.05$ vs the hypoxia group; ${ }^{\text {h}} P<0.05$ vs the moderately-high glucose group. Group $1=$ control; group $2=$ hypoxia; group $3=$ moderately-high $(15 \mathrm{mmol} / \mathrm{L}$ $D$-glucose) glucose; group $4=$ hypoxia + scutellarein $\left(1 \times 10^{-8} \mathrm{~mol} / \mathrm{L}\right)$; and group $5=$ moderately high $(15 \mathrm{mmol} / \mathrm{L})$ glucose + scutellarein $\left(1 \times 10^{-8} \mathrm{~mol} / \mathrm{L}\right)$.

scutellarein $\left(1 \times 10^{-8} \mathrm{~mol} / \mathrm{L}\right)$ significantly attenuated the VEGF concentrations in the supernatants of both the hypoxic and moderately-high glucose groups (Figure 6).

\section{Discussion}

HREC were employed in our current study in an effort to

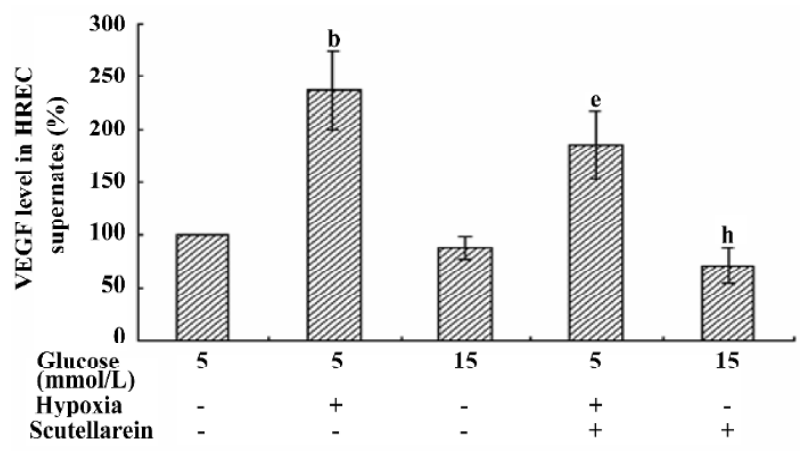

Figure 6. Effect of scutellarein on VEGF release by HREC. $n=5$. Mean \pm SD. ${ }^{\mathrm{b}} P<0.05$ vs control. ${ }^{\mathrm{e}} P<0.05$ vs the hypoxia group. ${ }^{\mathrm{h}} P<0.05$ $v s$ moderately-high glucose group.

understand the role of hypoxia and/or hyperglycemia in the pathogenesis of diabetic retinopathy. In an effort to explore the potential mechanism of action behind high glucose- and hypoxia-induced cell proliferation as well as the protection offered by scutellarein, the protein expression of VEGF was monitored. The levels of ocular VEGF, a key player in cell proliferation, are tightly correlated with both neovascularization and macular edema (secondary to increased vascular permeability). Thus VEGF may be identified as an important therapeutic target in ocular neovascu-larization and macular edema secondary to full-blown diabetes mellitus.

In the present study, moderately-high glucose $(15 \mathrm{mmol} / \mathrm{L})$ showed a significant increase in cell proliferation in HREC. Interestingly, there was no reminiscent proliferative effect when the cells were cultured with high glucose $(30 \mathrm{mmol} / \mathrm{L})$. This seemingly paradoxical finding is consistent with a previous finding ${ }^{[20]}$. One possible explanation may be due to the interaction between VEGF and the toxicity of glucose. In the case of moderately-high glucose, which represents clinical hyperglycemia in an untreated diabetic patient, endothelial cells may develop some degrees of tolerance for glucose toxicity. Therefore, the cell proliferation caused by VEGF appears to be dominant. On the contrary, our high glucose level was far beyond the physiologically tolerant range, in which case putrescence triggered by glucose toxicity may be dominant and shadows the effect on cell proliferation.

In our study, the concurrent exposure of high glucose and hypoxia failed to elicit any additive effect on cell proliferation in HREC compared with either high glucose or hypoxia alone. Such an observation seems to indicate that the 2 culprit stimuli may share similar mechanisms in promoting cell proliferation. Furthermore, these findings may also suggest that hypoxia is perhaps the most potent stimulus in the proliferation of HREC. It has been postulated that hypoxiainduced effects on cell proliferation are likely due to low 
oxygen tension-activated transcription factor HIF-1 $\alpha$ binding to its promoter region, which in turn facilitates transcription and consequently the translation of VEGF ${ }^{[21]}$.

Our data displayed a casual relationship between cell proliferation and the VEGF expression in response to hypoxia, high glucose, and scutellarein treatment, suggesting a likely role of VEGF in cell proliferation. VEGF and its receptors are present in retinal endothelial cells and may act through autocrine pathways to regulate cell survival and function. Although the precise role of VEGF in scutellarein-elicited protection against cell proliferation is still unclear, speculation, such as the inhibition of the PKC pathway may be considered at this time. The tyrosine kinase receptors for VEGF are believed to play a dominant role in VEGF signaling in endothelial cells. The activation of this signaling cascade leads to the tyrosine phosphorylation of phospholipase $\mathrm{C} \gamma$, the elevation of diacylglycerol levels, and the activation of PKC and other downstream signaling messengers ${ }^{[22]}$. A PKC dependence has been demonstrated for VEGF expression in vascular endothelial cells and retinal endothelial cells ${ }^{[23]}$. It has been reported ${ }^{[24]}$ that activated PKC- $\delta$ modulates the stability of HIF-1 $\alpha$ and enhances its transcriptional activity under hypoxic conditions in HeLa cells. This is supported by the fact that the knockdown of PKC- $\delta$ reduces the angiogenic activity by destabilizing HIF- $1 \alpha$ and downregulating the VEGF expression under hypoxia. Since scutellarein is capable of inhibiting $\mathrm{PKC}$, it is reasonable to speculate that scutellarein may achieve its beneficial antiproliferative effect by inhibiting the PKC signaling cascade. Scutellarein at the concentration range tested in our study, with the exception of $1 \times 10^{-4} \mathrm{~mol} / \mathrm{L}$, did not affect cell proliferation in normal cultured HREC, suggesting that scutellarein may not be innately harmful to healthy cells under normal physiological conditions. It is possible that the pharmacological concentration of $1 \times 10^{-4} \mathrm{~mol} / \mathrm{L}$ may elicit possible cytotoxic effects in vitro.

In conclusion, the present study using HREC demonstrates that scutellarein inhibits both cell proliferation and the VEGF expression in response to hypoxia and moderatelyhigh glucose. It is possible that the inhibition of the PKCdependent VEGF expression may underscore the beneficial effect of scutellarein. However, further study is warranted to elucidate the PKC isoforms involved in the action of scutellarein in order to better understand its therapeutic value.

\section{References}

1 The Diabetes Control and Complications Trial Research Group. The effect of intensive treatment of diabetes on the development and progression of long-term complications in insulin-de- pendent diabetes mellitus. N Engl J Med 1993; 329: 977-86.

2 Lu M, Kuroki M, Amano S, Tolentino M, Keough K, Kim I, et al. Advanced glycation end products increase retinal vascular endothelial growth factor expression. J Clin Invest 1998; 101: 1219-24.

3 Kern TS, Engerman RL. Capillary lesions develop in retina rather than cerebral cortex in diabetes and experimental galactosemia. Arch Ophthalmol 1996; 114: 306-10.

4 Agardh CD, Agardh E, Zhang H, Ostenson CG. Altered endothelial/pericyte ratio in Goto-Kakizaki rat retina. J Diabetes Complications 1997; 11: 158-62.

5 Bursell SE, Takagi C, Clermont AC, Tagaki H, Mori F, Ishii H, et al. Specific retinal diacylglycerol and protein kinase $\mathrm{C}$ beta isoform modulation mimics abnormal retinal hemodynamics in diabetic rats. Invest Ophthalmol Vis Sci 1997; 38: 2711-20.

6 Duh E, Aiello LP. Vascular endothelial growth factor and diabetes: the agonist versus antagonist paradox. Diabetes 1999; 48: 1899906.

7 Miller JW, Adamis AP, Aiello LP. Vascular endothelial growth factor in ocular neovascularization and proliferative diabetic retinopathy. Diabetes Metab Rev 1997; 13: 37-50.

8 Hammes HP, Lin J, Bretzel RG, Brownlee M, Breier G. Upregulation of the vascular endothelial growth factor/vascular endothelial growth factor receptor system in experimental background diabetic retinopathy of the rat. Diabetes 1998; 47: 401-6.

9 Gilbert RE, Vranes D, Berka JL, Kelly DJ, Cox A, Wu LL, et al. Vascular endothelial growth factor and its receptors in control and diabetic rat eyes. Lab Invest 1998; 78: 1017-27.

10 Enaida H, Kabuyama Y, Oshima Y, Sakamoto T, Kato K, Kochi $\mathrm{H}$, et al. VEGF-dependent signaling in retinal microvascular endothelial cells Fukushima. J Med Sci 1999; 45: 77-91.

11 Hata Y, Rook SL, Aiello LP. Basic fibroblast growth factor induces expression of VEGF receptor KDR through a protein kinase $\mathrm{C}$ and p44/p42 mitogen-activated protein kinase-dependent pathway. Diabetes 1999; 48: 1145-55.

12 Aiello LP, Northrup JM, Keyt BA, Takagi H, Iwamoto MA. Hypoxic regulation of vascular endothelial growth factor in retinal cells. Arch Ophthalmol 1995; 113: 1538-44.

13 Suzuma K, Naruse K, Suzuma I, Takahara N, Ueki K, Aiello LP, et al. Vascular endothelial growth factor induces expression of connective tissue growth factor via KDR, Flt1, and phosphatidylinositol 3-kinase-akt-dependent pathways in retinal vascular cells. J Biol Chem 2000; 275: 40725-31.

14 Chen XQ, Jin YY. The new edition of medicaments. 14th ed. Beijing: People's Medical Publishing House; 1997.

15 Wang GX. Pharmacologic action of breviscapine and clinic application. Lishizhen. Med Mater Med Res 1999; 10: 639-40.

16 Zhu BH, Guan YY, He H, Lin MJ. Erigeron breviscapus prevents defective endothelium-dependent relaxation in diabetic rat aorta. Life Sci 1999; 65: 1553-9.

17 Williams B, Gallacher B, Patel H, Orme C. Glucose-induced protein kinase $\mathrm{C}$ activation regulates vascular permeability factor mRNA expression and peptide production by human vascular smooth muscle cells in vitro. Diabetes 1997; 46: 1497-503.

18 Xia P, Aiello LP, Ishii H, Jiang ZY, Park DJ, Robinson GS, et al. Characterization of vascular endothelial growth factor's effect on the activation of protein kinase $\mathrm{C}$, its isoforms, and endothelial cell growth. J Clin Invest 1996; 98: 2018-26.

19 Li B, Tang SB, Zhang G, Chen JH, Li BJ. Culture and character- 
ization of human retinal capillary endothelial cell. Chin Ophthal Res 2005; 23: 20-2.

20 Premanand C, Rema M, Sameer MZ, Sujatha M, Balasubramanyam M. Effect of curcumin on proliferation of human retinal endothelial cells under in vitro conditions. Invest Ophthalmol Vis Sci 2006; 47: 2179-84.

21 Berra E, Pages G, Pouyssegur J. MAP kinases and hypoxia in the control of VEGF expression. Cancer Metastasis Rev 2000; 19 : 139-45.
22 de Vries C, Escobedo JA, Ueno H, Houck K, Ferrara N, Williams LT. The fms-like tyrosine kinase, a receptor for vascular endothelial growth factor. Science 1992; 255: 989-91.

23 Ishii H, Koya D, King GL. Protein kinase C activation and its role in the development of vascular complications in diabetes mellitus. J Mol Med 1998; 76: 21-31.

24 Lee JW, Park JA, Kim SH, Seo JH, Lim KJ, Jeong JW, et al. Protein kinase $\mathrm{C}-\delta$ regulates the stability of hypoxia-inducible factor-1 $\alpha$ under hypoxia. Cancer Sci 2007; 98: 1476-81.

17th International Symposium on Microsomes and Drug Oxidations

\author{
Saratoga, New York, USA
}

July 6-10, 2008

http://mdo2008.org 